ISSN No. 0974-035X

An indexed refereed \& peer-reviewed journal of higher education

Towards Excellence

UGC-HUMAN RESOURCE DEVELOPMENT CENTRE

Gujarat University, Ahmedabad-380009, Gujarat, India

\title{
NATURE OF SUPERHEROES \\ ANALYSIS OF THE UMBRELLA ACADEMY IN AGE OF SUPERHERO CRISIS
}

\author{
Dr. Naresh M. Solanki
}

\begin{abstract}
Hero and heroism have been one of the oldest themes in literatures across the world. However, Comics, movies and other media have highlighted those to a hyperbolic level, turning allegorical in make-believe and vice versa. After critical and commercial success of various adaptations of Marvel and DC comics properties there has been a wave of alternative comic adaptations like Watchmen (2020), The Boys (2020) and The Umbrella Academy (2019), marking a different take on fictional superheroes. This critical paper studies that alternative stand taken by these adaptations and theorizes how these texts are critiquing the genre itself.
\end{abstract}

Keyword: Superhero, Genre, Meta-studies, Film studies, Cultural studies

Hero or superhero is one of the primary archetypes in literature across the world. Myth has used it abundantly, so has comic books. The boom in the comic to screen adaptation has come to a halt with the release of (2020). There have been more than a hundred adaptations of the comic or otherwise superhero fiction in films, television, and web series format. This large scale practice has multiple effects on culture in general, especially on the very concept of the superhero.

The medium of audio-video provides a unique opportunity for the source material. The action depicted on the pages with ink and colors can be shown as 'real' in the live-action format through the usage of VFX and computer-generated imagery. By large superheroes, films and television series are part of fantasy fiction, as myths are. This genre bounds them into some convention which is more or less followed by creators. For example, superheroes by definition are good and villains are bad. If this convention is subverted as in Megamind (2010), then it may find mild responses from the audience. This is peculiar of the popular culture where a significant amount of the old stories are told again and again because popular space celebrates archetypes, not individual plot.

The Umbrella Academy (2019) is a web series produced and distributed by major OTT platforms Netflix. It is about the lives of some gifted children with special powers, time travel, daddy issue, and some historical-cultural contexts like Kennedy's assassination. They race against (or through) time to stop an apocalypse. It is a drama, or more accurately a melodrama series. 
As Casey describes a melodrama can be a mixture of romance, sensationalism, intensity, overblown action, suspense, and tragedy. He argues for it to be considered as a style or aesthetics rather than a genre. The Umbrella Academy is an audio-visual text therefore we can see a distinct visual style in the narrative. For example, fight scenes use low and high angle when over the top action is seen on the screen. It provides a clear view of direction by slowing the framerate at the moment of intensity like a punch being delivered. Thus, it emphasizes the intensity by slowing the motion in the frame.

The prologue of the text can be seen as absurd. Instead of opening it in America, where the series is set, it opens in Russia. A swimmer girl who is perfectly fine at one moment gives birth to a child without any trace of pregnancy, though she has to go through labor pain. This is symbolic of creativity. The simple relation of cause and effect, pregnancy, and childbirth allude to the idea and creation of a work. Here, but cutting that relation the text establishes itself as a postmodern text.

However, it uses the tropes of classic family drama. The relation between Reggie Hargreaves and his adopted children is the center of the narrative. It presents several different takes on the father-child relationship, in the strictest form of patriarchy. This is evident from the fact that the role of mother is provided by a servant robot Grace instead of a real human female. This brings the question of gender later when it is revealed that Reggie is not a human but an alien disguised as one.

The plot structure of the text also shows why it is a postmodern text. It even reverts it attempted story in the episode titled 'The day that was' which erases the events that happened in the previous episode titled 'The Day That Wasn't'. Also, an ample amount of footage is used for flashbacks which almost establishes a timeline other than the present one but never settles on it. It is an active comment on the past, where it comes to haunt the present but one can not make it a place of escape as Luther wants.

If the plot structure is fragmented then perspective or point of view are almost scattered. Initial watching may confuse the viewers on who the main character or protagonist is. The hierarchy established by the number given to children proves fruitless as there is no clear distinction or order between them. Number five and six are missing from the lot. That confusion is deliberate as the presence of both the characters that 'five' and Ben are absent in terms of time and space respectively. Otherwise, they are present in the narrative. As Derrida says, 'The absence is the presence.' Relating the idea of fragmented reality is important in the course of the text, especially after the arrival of Number Five, who is an eighty-five-year-old man trapped in a teenager's body due to an error in the equation while traveling through time.

Time itself is a fragmented or an uneven object, which is being controlled by the commission. The commission is an agency that maintains the timeline by protecting events as they should happen. The nature of its work is liberating yet binding as field agents can go anywhere in time but are bound to follow directions given by executives. Characters of Chacha and Hazel are the only field operatives that have sufficient screentime to comment about. They are a representation of the present working class in industries like technology, sales, education, consulting, etc. Their well-worn suits are in contrast with their murderous ways of working, which is part of their job description. This all works well just because of the assumption that the protagonist group is 'superheroes'. A superhero is defined as

'a person or other living or dead entity in a fictional universe who has some special ability, power, skill etc which can be used for the welfare of the humankind.' 
This definition provides a constructive perspective on the idea of a superhero. They seem to be perfect for normal people i. e. people in a fictional universe who doesn't have any superpower or special ability. The text in the questions sets out to deconstruct it.

The titular team is shown to struggle with their lives as adults. Luther has no social life, he is literally sent to the moon. Diego becomes attached to the idea of being the ideal hero in his own version of the scheme, he can not fathom the difference between real and ideal. Allison has taken up a film career and become a Hollywood star, which is an alternative form of role model. Klaus has wasted his potential by the usage of drugs and alcohol. Vanya has no power, so she becomes a less influential figure than her siblings. This set up deliberately misses the two siblings who have matured well compared to their siblings. Ben, being a ghost has a different perception of reality and keeps guiding Klaus in the right direction. Another mature sibling is Five, who has no other name. Which itself is a marker of his maturity. He doesn't need a name as he is not participating in the hierarchy established by the number given to them. His old age and teenage body create a comic conflict.

Every sibling has a dependent identity, they either define themselves against their other siblings, individually or collectively or they define themselves against their father figure. The patriarch Reggie Hargreaves becomes a life long influence that even after his death, he continues to impact their lives. For Luther he is the ideal and perfect man to follow, that's why he gets to the red herring of murder theory when Reggie dies. It is a form of denial that his father is dead. Against that Diego has clear scorn for the father figure. The reason for his scorn seems to be a lack of trust or praise from the father figure which motivates the child. The trust is broken between them, that's why he wants to prove his worth by being a 'hero' which also comes from his rivalry with Luther. As Diego is number two he is always one step from the top spot. Allison and Klaus choose not to define themselves and even tries to burry the powers they have been gifted. Vanya being the only one without powers feels left out hence her writing a book on her childhood can be seen as a purging of the detestation of her childhood memories.

Five is the protagonist of the text. He is the one who moves the plot forward with his arrival to the present time. The idea of apocalypse in 2019 is put forth and the reaction of various characters is typical of what they think about their role as a hero. A flourished team of once-popular superheroes are broken individuals now. Texts become a metatext as it comments upon the genre of superhero movies and series. The grandeur of the superhero genre is reduced to the loathsome loneliness of broken people. This is the argument of the text, superheroes are not born, but made and can be unmade. The fight between siblings and ChachaHazel clears that it is not solely their abilities but their existence as a team which made them powerful over calamities and threats. There is no clear antagonist which often fills the role of a supervillain in the genre. But as there is no clear antagonist the drama and tension come from the mundane life of extraordinary siblings. There are threefold opposite sides. There Chacha-Hazel who are more like henchmen/women as they are following orders, Second is the Handler who has literal control over time and third is Harold Jenkins who uses Vanya to get his revenge on the umbrella academy. We can see a clear line established between characters becoming agonistic and being a supervillain. Even Reggie Hargreaves can be said to have filled that role as his actions continue to hurt the siblings in their adult lives.

Thus, this text breaks the dual-lateral structure of superhero movies and series genre where good and evil are defined. Here the text uses postmodern techniques to establish that there is no clear distinction between them. This even makes it more clear that this text functions as a metatexts on the genre. It even provides a critique of the genre by using the tropes and then subverting them. For example, when Five kills the board of 
commissioners to get a briefcase to get back to 2019, he has one hour to gather all his siblings. It is a minor task but has a familiar element for the genre audience, which is of ticking clock. The ordinary task of getting together is simple enough for extra-ordinary siblings, yet they fail. It clearly denotes how superheroes despite saving the world are not as perfect as being, the text gives the message that everyone can fail.

That is why The Umbrella Academy can be considered an important text in the history of the genre. It works not only as an adaptation of comics with the same title but also becomes a parody of superhero franchises like X-men.

In conclusion, the text has been structured in a way that helps creators critique the genre it resides. It critiques the social order found in the new corporate cubical culture, it also analyses the dysfunctional family structure which is a product of the modern age. More than that it critiques the concept of superhero and finds instances which are anomalies with implications of realism mixed with surrealism. 


\section{Solanki / Page 167-171}

\section{Bibliography}

- Blackman, Steve. Slater, Jeremy. 2019 The Umbrella Academy Netflix

- Burke, Liam. 2008 Superhero Movies. Pocket Essentials

- Hayward, Susan. 2000 Cinema Studies: The Key Concept Routledge

- Klock, Geoff. 2013 “The Revisionary Superhero Narrative” The Superhero Reader. University Press of Mississippi

- McGrath, Tom. 2010 Megamind. Dreamwork Animation

- Watts, Jon. 2019 Spiderman: Far From Home. Marvel Entertainment

\section{Dr. Naresh M. Solanki Head, Department of English, Dr. Subhash Mahila Arts, Commerce and Science College. Junagadh nareshsolanki456@gmail.com}

